\title{
BMJ Open A cross-sectional study on risk factors and their interactions with suicidal ideation among the elderly in rural communities of Hunan, China
}

\author{
Huilan Xu, Lulu Qin, Jinhong Wang, Liang Zhou, Dan Luo, Mi Hu, Zhenhua Li, \\ Shuiyuan Xiao
}

To cite: Xu H, Qin L, Wang J, et al. A cross-sectional study on risk factors and their interactions with suicidal ideation among the elderly in rural communities of Hunan, China. BMJ Open 2016;6: e010914. doi:10.1136/ bmjopen-2015-010914

- Prepublication history for this paper is available online. To view these files please visit the journal online (http://dx.doi.org/10.1136/ bmjopen-2015-010914).

Received 21 December 2015 Revised 19 March 2016 Accepted 23 March 2016

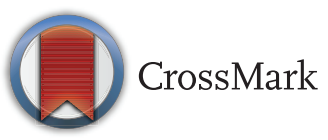

Department of Social Medicine and Health Management, Xiangya School of Public Health, Central South University, Changsha, Hunan, China

Correspondence to Huilan Xu;

xhl6363@126.com

\section{ABSTRACT}

Objectives: To identify risk factors, and their interactions, for suicidal ideation among the elderly in rural communities of Hunan and to provide some scientific basis for suicide prevention.

Design, setting and participants: A cross-sectional survey was conducted among the elderly in rural communities in China's Hunan Province. Thirteen areas were selected by multi-staged cluster random sampling, and 1887 rural elders were investigated via face-to-face interviews.

Main outcome measures: Measures included sociodemographic information, suicidal ideation, activities of daily living (ADL), major depression disorder (MDD), drinking, stressful life events and social support. Non-conditional logistic regression was preformed to explore the influencing factors for suicidal ideation, and additive interaction was used to analyse the interaction between risk factors.

Results: Incidence of suicidal ideation among the elderly was $14.5 \%(95 \% \mathrm{Cl} 12.9 \%$ to $16.1 \%)$ in rural communities of Hunan. The independent influencing factors for suicidal ideation were annual personal income (OR 3.14; 95\% Cl 2.15 to 4.59), MDD (OR $17.04 ; 95 \% \mathrm{Cl} 11.91$ to 24.39 ), chronic diseases (OR 2.99; $95 \% \mathrm{Cl} 1.84$ to 4.85 ) and ADL (OR 2.00; $95 \% \mathrm{Cl} 1.37$ to 2.94$)$. Additive interactions were detected between MDD and ADL with a relative excess risk of interaction (RERI) of $21.18(95 \% \mathrm{Cl} 5.47$ to 36.89), and between MDD and annual personal income with an RERI of 35.00 (95\% Cl 9.00 to 61.00$)$.

Conclusions: The independent risk factors for suicidal ideation are annual personal income $(\leq 2200$ CNY), MDD, chronic diseases and disabled ADL status. MDD has additive interactions with ADL and annual personal income. These findings have significant implications for the prediction and prevention of suicidal behaviours.

\section{INTRODUCTION}

Suicide has become a major public health and social problem worldwide. ${ }^{1}$ It accounts

\section{Strengths and limitations of this study}

- This is the first study to examine the risk factors, and their interactions, for suicidal ideation among the elderly in rural communities in China. Owing to the population-based, large-scale design, the highly standardised methods, and the high rate of follow-up, these findings should be helpful for preventing suicide in rural-living elderly Chinese.

- The study provides valuable information on rate of suicidal ideation, influencing factors and interactions between these factors among the elderly in rural communities.

- The additive interactions (the relative excess risk due to interaction (relative excess risk of interaction (RERI)), the attributable proportion due to interaction (AP) and the synergy index (S)) are used to analyse the interaction between risk factors and suicidal ideation.

- The study is limited by its cross-sectional and self-reported design.

for $3.6 \%$ of all deaths and is the fifth most common cause of death in China ${ }^{2}$; statistical figures have shown that the suicide rate is about 22/100 000 per year. $^{3}$ There is a gradual process of development from suicidal ideation to suicide attempt, ${ }^{4}$ and $60 \%$ of transitions from ideation to planning and attempt occur within the first year after ideation onset. ${ }^{5}$ Suicidal ideation is one of the most important risk factors for suicide ${ }^{6}$ and also an evaluation index recommended by the WHO.

With the worldwide awareness of suicide and increasing numbers of studies on suicidal behaviours in Western and high-income countries, ${ }^{7-9}$ studies on suicidal problems have also been springing up in China. With the aging of the population of China, the prevalence of suicide among the elderly is high, with the rate ranging from $2.2 \%$ to 
$21.5 \%$, higher than in urban areas or other age groups. ${ }^{10}$ Thus, more attention should be paid to the prevalence of suicide among rural-dwelling older people.

Intervention in suicidal ideation is the key process in suicide intervention, which is also considered to be the most effective measure to prevent suicide. ${ }^{4}{ }^{10}$ Studies have shown that many factors influence suicidal ideation among the elderly, such as gender, disease, economic status, physical health, activities of daily living (ADL) status, mental health and so on, ${ }^{9-11}$ and they can be categorised into three groups-psychosocial factors, social-environmental factors and sociodemographic factors ${ }^{11}$ - which may also have connections with each other. It has also been shown that ADL has a strong association with depression disorder. ${ }^{12}$ Moreover, factors such as negative life events, low social support, weak physical condition, low income, and chronic diseases, are risk factors for both depression and suicidal ideation among the elderly. ${ }^{113}$ Capron et al $^{14}$ found that anxiety sensitivity physical scores showed an interaction with anxiety sensitivity cognitive scores. Interactions of risk factors are useful and effective for preventing suicidal ideation. Only a few studies have focused on such interactions and there is a lack of research on risk factors, and their interactions, for suicidal ideation among ruralliving elderly Chinese.

This study was conducted in Hunan, a typical south central province in China. The geographical position of Hunan is from $24^{\circ} 38^{\prime}$ to $30^{\circ} 08^{\prime} \mathrm{N}$ latitude and from $108^{\circ}$ $47^{\prime}$ to $114^{\circ} 15^{\prime} \mathrm{E}$ longitude. The total population of Hunan is 71 million, with $9.99 \%$ aged 65 or older and an increasing proportion of elderly people. Moreover, the gross domestic product (GDP) of Hunan ranked 10th among the provinces in China in 2011 with a per capita GDP of $29880 \mathrm{CNY}$ per person, a medium level for the country. A previous study showed that the average suicide rate in the elderly in rural areas (88.3/ $100000)$ was four times higher than in urban areas $(24.4 / 100000) .{ }^{15}$ In addition, it has been shown that the prevalence of suicidal ideation among the elderly has increased from $8.7 \%$ to $21.5 \%$ in rural areas in Hunan, ${ }^{16}$ from which we can conclude that suicide is becoming an important public health problem in this population. Therefore we carried out this study to investigate risk factors and their additive interactions with suicidal ideation among the elderly in rural communities of Hunan. We hope this study can also provide some scientific basis for suicide prevention for rural-dwelling elderly in China.

\section{METHODS}

\section{Sample size calculation}

In order to address suicidal ideation among the rural elderly, sample size was calculated by estimating an incidence rate with specified relative precision for crosssectional studies according to WHO-recommended tools: a sample of 1537 would be needed for $\alpha=0.05$ and $\varepsilon=0.05$. ${ }^{16}$ The theoretical sample was 1844 after increasing the number of observed subjects by $20 \%$ to account for subjects lost during the investigation.

\section{Participants}

A cross-sectional survey was conducted among the elderly in rural communities of Hunan Province. By multi-staged cluster sampling, two counties (Hengyang and Liuyang) were randomly selected from the 122 counties in Hunan Province. Next, three townships (Yanshan, Qulou and Qulan) were randomly selected from the 26 townships in Hengyang, and three villages were chosen from the selected townships. Concurrently, two townships (Gaoping and Yongan) were randomly selected from the 24 townships in Liuyang, and two villages were chosen from the selected townships; two teams were randomly selected from each village. In total, 13 areas were selected for our study. The elderly (age $\geq 60$ years) resident population (who had achieved registered permanent residence or had not achieved registered permanent residence but had resided there for 6 months) were identified as our subjects, but those with severe physical or mental illness were excluded. There were 2235 elderly residents in the 13 selected areas, of which 198 were excluded because of severe physical or mental illness. The theoretical sample size was 2037 people, with 150 not investigated for various reasons (figure 1). The response rate was $92.6 \%$ $(1887 / 2037)$. Of the remaining 1887 individuals, eight were excluded for incomplete data. In total, 1879 elderly were used in the statistical analysis and the effective rate was $99.6 \%$ (1879/1887). Our pretrained interviewers went to the homes of the elderly subject's to explain carefully the aim and plan of the study and the interests and rights of the participants. They then interviewed participants face to face after each participant had given written informed consent. If the participants were

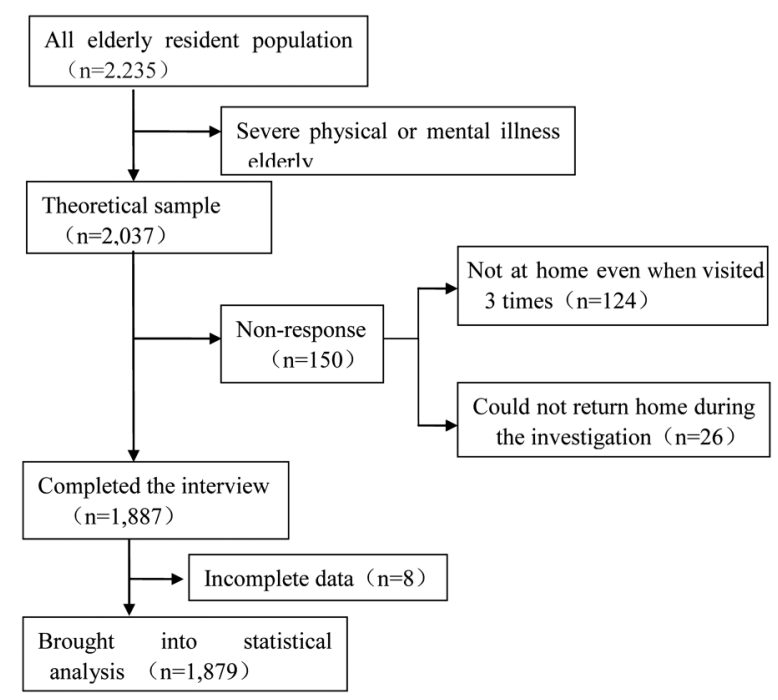

Figure 1 Response of subjects. 
illiterate, the written consent form was signed by a family member. The elderly had the right to decline to participate in the study without any penalty, and they could drop out if they wanted to at any time during the investigation. Consequently, all procedures were performed in accordance with ethics standards. If the individual was not at home, we would record the reason. Our interviewers were required to check their questionnaires carefully every day. The survey was carried out from 2009 to 2011.

\section{Measures}

Participants were asked for general information and about suicidal ideation, ADL, major depression disorder (MDD), drinking, stressful life events and social support. The components of the questionnaire relevant to this study are detailed below.

\section{General information}

Name, sex, age, marital status, educational status, annual personal income, chronic disease and whether the subject lived alone or not were measured by a selfdesigned inventory. Chronic disease refers to chronic non-communicable diseases, including cardiovascular disease, cancers, chronic obstructive pulmonary disease, type 2 diabetes and others (namely, diseases according to classification standards included in the ICD-10). Living alone is defined as a social situation where a person lives in a dwelling without a cohabitant, children or other household members. According to the international poverty line standard (the median income or $50 \%$ of the average income), the poverty line in rural areas in Hunan was $2200 \mathrm{CNY} /$ year per person in 2011, so we defined low income as income lower than 2200 $\mathrm{CNY} /$ year per person.

\section{Suicidal ideation}

According to the concept and classification of suicidal behaviour, ${ }^{17}$ we defined suicidal ideation as the thought of suicide or wanting to take actions to end one's life. We developed a self-made suicidal behaviour questionnaire which contained four items: suicidal ideation (Have you ever seriously considered suicide in the last 12 months?), suicidal plan (Have you ever made a plan for committing suicide in the last 12 months?), suicidal preparation (Have you ever prepared any tool to kill yourself in the last 12 months?) and attempted suicide (Have you ever attempted suicide?). The response options were yes and no.

\section{Activities of daily living}

ADL of the elderly was measured by Lawton and Brody's ADL scale, which includes 14 items. ${ }^{18}$ It consists of a physical self-maintenance scale and an instrumental ADL scale. Each item was scored from 1 to 4 . A total score higher than 14 was defined as disabled; otherwise the individual was considered normal.
Major depression disorder

MDD was measured by the Chinese version of the Patient Health Questionnaire-9 (PHQ-9), the reliability and validity of which are high. ${ }^{19}{ }^{20}$ PHQ-9 has two parts. The first part consists of nine items for assessing the frequency of depression symptoms; each item is scored from ' 0 ' (not at all) to ' 3 ' (nearly every day). The second part has an additional item: 'How difficult was it for you to do your work, take care of things at home, or get along with other people?' It is also scored from ' 0 ' (not difficult at all) to ' 3 ' (extremely difficult). Diagnosis of MDD had to satisfy the following three requirements simultaneously: (1) at least five items with scores $\geq 2$ in the first part (including if the ninth item scored $\geq 1$ ); (2) at least one of the first or second items with a score $\geq 2$; and (3) the second part with scores $\geq 2$. $^{21}$

\section{Drinking}

The alcohol use disorders identification test (AUDIT) developed by the WHO is considered a convenient method of screening for excessive drinking. It contains 10 test items the reliability and validity of which have been established in research conducted in a variety of settings and many different nations. ${ }^{22}$ In China, an AUDIT score $>7$ is regarded as indicating hazardous and harmful drinking.

\section{Stressful life events}

On the basis of previous scales, ${ }^{23}{ }^{24}$ we listed 38 life events and summarised them into three aspects: health-related problems, problems related to marital and family life, and social and other problems. If any of these events occurred in a subject and they felt stressed, we concluded that the subject suffered from stressful life events.

\section{Social support}

The Social Support Rating Scale ${ }^{25}$ has proven high reliability and validity in China. The scale includes three parts: objective support, subjective support, and availability of social support. If an individual's social support score is lower than the mean, we define the person as having low social support, otherwise the individual is considered to have high social support.

\section{Statistical analysis}

Data were created and analysed using SPSS statistical software V.16.0. A significance threshold of group differences was set at $\mathrm{p}<0.05$ (bilateral). There were six age categories $(60-64,65-69,70-74,75-79,80-84,85$ and above), two annual personal income categories (0-2200, 2201 and above), four education status categories (illiterate, primary school, junior high school, senior high school and/or above), and two marital status categories (stable marriage, unstable marriage). Stable marriage meant complete marriage, while unstable marriage was widowed, unmarried or divorce. 
Univariate and multivariate non-conditional logistic regression were used to explore factors influencing suicidal ideation. In order to examine the relationships between risk factors and suicidal ideation, we estimated ORs and 95\% CIs using univariate and multivariate non-conditional logistic regression. There are three measures for testing additive interaction: the relative excess risk due to interaction (RERI); the attributable proportion due to interaction (AP); and the synergy index $(\mathrm{S})$. There is no additive interaction if RERI and $\mathrm{AP}$ are equal to 0 , or $\mathrm{S}$ is equal to 1 . We inputted the regression coefficients and covariance matrix drawn from the logistic regression into the Excel sheet created by Andersson et $a l^{26}$ to calculate the interaction of risk factors (annual personal income, chronic disease, MDD, ADL) and their CIs.

\section{RESULTS}

A total of 1879 individuals aged 60-97 years were included in the study. They had a median age of 69 years, and $891(47.4 \%)$ were female. According to the poverty line $(\leq 2200 \mathrm{CNY})$ in rural areas in Hunan, $953(50.7 \%)$ were low income. Most $(1331(70.8 \%))$ had stable marriages. There were four education levels: 650 $(34.6 \%)$ were illiterate, $1034(70.8 \%)$ had finished primary school, $161(8.6 \%)$ had finished junior high school, and $34(1.8 \%)$ had finished senior high school and/or above. In total, $232(12.3 \%)$ subjects were living alone, $236(12.6 \%)$ had MDD, $1316(70.0 \%)$ had chronic diseases, $1019(54.2 \%)$ had disabilities in ADL, $177(9.4 \%)$ suffered from hazardous and harmful drinking, and $1637(87.1 \%)$ had experienced negative life events in the past year. Social support scores ranged from 17 to 61 (mean 40); $997(53.1 \%)$ had low social support (table 1).

\section{Incidence of suicidal ideation}

The incidence of suicidal ideation was $14.5 \%$ (95\% CI $12.9 \%$ to $16.1 \%$ ), and the data from the Chinese census in 2000 showed that it fell to $14.1 \%$ after standardisation. The incidence of suicidal plan, suicidal preparation and attempted suicide were $4.0 \%, 1.9 \%$ and $0.8 \%$, respectively. In the suicidal ideation group, $27.6 \%$ (75/272) had made a suicidal plan, $12.9 \%$ (35/272) had prepared for suicide, and $5.6 \%(15 / 272)$ had attempted suicide.

\section{Factors influencing suicidal ideation}

There were no statistically significant differences in sex, age, drinking and social support between the suicidal ideation group and the control group (all significant at $p>0.05$ ). As indicated in table 2 , the factors influencing suicidal ideation among the elderly were having an MDD (OR 19.53; 95\% CI 14.19 to 26.88), suffering from chronic diseases (OR 4.93; 95\% CI 3.25 to 7.60 ), disabled ADL status (OR 3.96; 95\% CI 2.90 to 5.41), annual personal income (OR 4.44; 95\% CI 3.26 to 6.04 ), unstable marriage (OR 1.846; 95\% CI 1.42 to 2.41),

\begin{tabular}{|c|c|c|}
\hline Variable & $\mathbf{n}$ & Per cent \\
\hline \multicolumn{3}{|l|}{ Age (years) } \\
\hline $60-69$ & 993 & 52.8 \\
\hline $70-79$ & 681 & 36.2 \\
\hline$\geq 80$ & 205 & 11.0 \\
\hline \multicolumn{3}{|l|}{ Gender } \\
\hline Male & 988 & 52.6 \\
\hline Female & 891 & 47.4 \\
\hline \multicolumn{3}{|l|}{ Annual personal income (CNY) } \\
\hline 2201 and above & 926 & 49.3 \\
\hline $0-2200$ & 953 & 50.7 \\
\hline \multicolumn{3}{|l|}{ MDD status } \\
\hline No & 1643 & 87.4 \\
\hline Yes & 236 & 12.6 \\
\hline \multicolumn{3}{|l|}{ History of chronic diseases } \\
\hline No & 563 & 30.0 \\
\hline Yes & 1316 & 70.0 \\
\hline \multicolumn{3}{|l|}{ ADL status } \\
\hline Normal & 860 & 45.8 \\
\hline Disabled & 1019 & 54.2 \\
\hline \multicolumn{3}{|l|}{ Marital status } \\
\hline Stable marriage & 1,331 & 70.8 \\
\hline Unstable marriage & 548 & 29.2 \\
\hline \multicolumn{3}{|l|}{ Educational status } \\
\hline Illiterate & 650 & 34.6 \\
\hline Primary school & 1034 & 70.8 \\
\hline Junior high school & 161 & 8.6 \\
\hline Senior high school and/or above & 34 & 1.8 \\
\hline \multicolumn{3}{|l|}{ Living alone } \\
\hline No & 1647 & 87.7 \\
\hline Yes & 232 & 12.3 \\
\hline \multicolumn{3}{|l|}{ Stressful life events } \\
\hline No & 242 & 12.9 \\
\hline Yes & 1637 & 87.1 \\
\hline \multicolumn{3}{|l|}{ Hazardous and harmful drinking } \\
\hline No & 1702 & 90.6 \\
\hline Yes & 177 & 9.4 \\
\hline \multicolumn{3}{|l|}{ Social support scores } \\
\hline High (>40) & 882 & 46.9 \\
\hline Low $(\leq 40)$ & 997 & 53.1 \\
\hline
\end{tabular}

finishing primary school (OR $0.59 ; 95 \%$ CI 0.45 to 0.78 ) and junior high school (OR $0.37 ; 95 \%$ CI 0.20 to 0.67 ), living alone (OR 2.50; 95\% CI 1.80 to 3.45 ) and experiencing negative life events in the past year (OR 2.02; $95 \%$ CI 1.25 to 3.25$)$. The multivariate non-conditional logistic regression analysis showed that the independent risk factors for suicidal ideation were annual personal income $\leq 2200 \mathrm{CNY}$ (OR 3.14; 95\% CI 2.15 to 4.59), having an MDD (OR 17.04; 95\% CI 11.91 to 24.39), suffering from chronic diseases (OR 2.99; $95 \%$ CI 1.84 to 4.85 ) and disabled ADL status (OR 2.00; 95\% CI 1.37 to 2.94), when other variables, such as sex, age, marital status, educational background, annual personal income, history of chronic disease, living status, history of an MDD, ADL, drinking, stressful life events and social support, were controlled for. 
Table 2 Influencing factors for suicidal ideation (SI)

\begin{tabular}{|c|c|c|c|c|}
\hline Variable & Participants (n) & $\begin{array}{l}\text { Prevalence } \\
\text { of SI (\%) }\end{array}$ & Crude OR (95\% Cl) & Adjusted OR ${ }^{\star}(95 \% \mathrm{Cl})$ \\
\hline \multicolumn{5}{|l|}{ Annual personal income (CNY) } \\
\hline $0-2200$ & 953 & 22.6 & $4.44(3.26$ to 6.04$) \dagger$ & $3.14(2.15$ to 4.59$) \dagger$ \\
\hline \multicolumn{5}{|l|}{ MDD status } \\
\hline No & 1643 & 7.7 & 1.00 (reference) & 1.00 (reference) \\
\hline No & 563 & 10.7 & 1.00 (reference) & 1.00 (reference) \\
\hline Yes & 1316 & 15.9 & $4.93(3.25$ to 7.60$) \dagger$ & $2.99(1.84$ to 4.85$) \dagger$ \\
\hline \multicolumn{5}{|l|}{ ADL status } \\
\hline Normal & 860 & 6.4 & 1.00 (reference) & 1.00 (reference) \\
\hline Disabled & 1019 & 21.3 & $3.96(2.90$ to 5.41$) \dagger$ & $2.00(1.37$ to 2.94$) \dagger$ \\
\hline Illiterate & 650 & 19.4 & 1.00 (reference) & 1.00 (reference) \\
\hline Primary school & 1034 & 12.5 & $0.59(0.45$ to 0.78$) \ddagger$ & $0.75(0.52$ to 1.09$)$ \\
\hline Junior high school & 161 & 8.1 & $0.37(0.20$ to 0.67$) \ddagger$ & $0.69(0.326$ to 1.45$)$ \\
\hline Senior high school and/or above & 34 & 11.8 & $0.55(0.19$ to 1.61$)$ & $0.49(0.13$ to 1.90$)$ \\
\hline \multicolumn{5}{|l|}{ Living alone } \\
\hline No & 1647 & 14.1 & 1.00 (reference) & 1.00 (reference) \\
\hline Yes & 232 & 17.2 & $2.50(1.80$ to 3.45$) \dagger$ & $1.36(0.84$ to 2.20$)$ \\
\hline \multicolumn{5}{|l|}{ Stressful life events } \\
\hline No & 242 & 8.3 & 1.00 (reference) & 1.00 (reference) \\
\hline Yes & 1637 & 15.4 & $2.02(1.25$ to 3.25$) \dagger$ & $0.84(0.48$ to 1.48$)$ \\
\hline
\end{tabular}

Interaction of risk factors (annual personal income, MDD, ADL and chronic diseases) with suicidal ideation

In this study, multivariate non-conditional logistic regression was used to calculate the regression coefficients and covariance matrix after adjustment. The adjusted factors include all the factors mentioned above except for two that would examine the interaction between them. Microsoft Excel was used to calculate RERI, AP and S, and their CIs were based on the results from the logistic regression. Additive interactions were detected between MDD and ADL with an RERI of 21.18 (95\% CI 5.47 to 36.89 ), AP of 0.63 (95\% CI 0.39 to 0.88 ), and S of 2.84 (95\% CI 1.40 to 5.85). Additive interactions were also detected between MDD and annual personal income with an RERI of 35.00 (95\% CI 9.00 to 61.00 ), AP of 0.66 (95\% CI 0.46 to 0.85 ), and S of 3.03 (95\% CI 1.68 to 5.47) (table 3).

\section{DISCUSSION}

For this study, we used multi-staged cluster sampling, with the selected samples in Hengyang and Liuyang representing the rural communities of Hunan, China. In addition, we complied with severe quality control to maintain the verity of the data. There was a low non- response rate $(7.4 \%)$ but a high data efficient rate $(99.5 \%)$. We used a cross-sectional study with unavoidable recall bias, because suicidal ideation is innate according to the memory of subjects and can be influenced by recent events.

The incidence of suicidal ideation among the elderly is $14.5 \%$ in rural communities of Hunan and fell to $14.1 \%$ after standardisation. Kjoller and Helweg-Larsen ${ }^{27}$ reported that $6.9 \%$ of adults had had suicidal thoughts within the past few years in Denmark, Goldney et $a l^{28}$ found that $5.6 \%$ of men and $5.3 \%$ of women had suicidal ideation in south Australia, and O'Connell et $a l^{29}$ reported that the prevalence of suicidal ideation among elderly people varies from $1.2 \%$ to $17 \%$. Therefore, from previous studies, we can conclude that the incidence of suicide ideation among the elderly in rural communities is high. Meanwhile, in our stuffy, hazardous and harmful drinking, stressful life events and social support were not detected as independent risk factors for suicide ideation, which is in contradiction with some studies. ${ }^{30} 31$ The reason may be different cultures and features in different districts and the disparity in the design of the methods and the scales used.

Low annual personal income is an independent risk factor for suicidal ideation, which is in agreement with 
Table 3 Interaction of risk factors for suicidal ideation

\begin{tabular}{|c|c|c|c|c|c|}
\hline Factor 1 & Factor 2 & OR $^{*}$ & RERI & AP & $\mathbf{S}$ \\
\hline MDD status & ADL status & & 21.18 (5.47 to 36.89 ) & $0.63(0.39$ to 0.88$)$ & $2.84(1.40$ to 5.85$)$ \\
\hline+ & + & 33.55 (20.05 to 56.14$) \dagger$ & & & \\
\hline- & + & 1.73 (1.12 to 2.69$) \ddagger$ & & & \\
\hline+ & - & 11.64 (5.76 to 23.52$) \dagger$ & & & \\
\hline- & - & 1.00 & & & \\
\hline MDD status & $\begin{array}{l}\text { Annual personal } \\
\text { income }\end{array}$ & & 35.00 (9.00 to 61.00$)$ & $0.66(0.46$ to 0.85$)$ & 3.03 (1.68 to 5.47$)$ \\
\hline+ & + & 53.25 (30.27 to 93.66)† & & & \\
\hline- & + & $3.05(1.92$ to 4.85$) \dagger$ & & & \\
\hline+ & - & 16.20 (8.66 to 30.30$) \dagger$ & & & \\
\hline- & - & 1.00 & & & \\
\hline
\end{tabular}

conclusions from previous studies. $^{32}$ In the present study, people with an annual personal income $\leq 2200$ CNY were more likely to have suicidal ideation than those with an income $>2200 \mathrm{CNY}$ (adjusted OR (aOR) $3.14 ; 95 \%$ CI 2.15 to 4.59$)$. The reason may be that people with a low income may have more family conflicts and diseases that may not be treated in time. ${ }^{33}$ In addition, economic stress is also associated with depression, with evidence showing that financial strain and unemployment are causally related to depression. ${ }^{34}$ ADL is also an independent risk factor for suicidal ideation; people with disabled ADL status have a higher risk of developing suicidal ideation than those with normal ADL (aOR 2.00; 95\% CI 1.37 to 2.94). The study by Awata $e t a l^{35}$ showed the same result. Dennis et $a l^{36}$ showed that the strength of association between suicidal ideation and ADL limitation increased with the number of daily activity domains affected and was of similar magnitude for most individual domains.

MDD' has been previously accepted as an independent risk factor for suicidal ideation. ${ }^{37} 38$ In the present study, people with MDD had a higher risk of developing suicidal ideation than those without (aOR 17.04; 95\% CI 11.91 to 24.39 ). We also discovered that MDD is not only an independent risk factor for suicidal ideation but also has additive interactions with annual personal income and ADL. The aORs for interaction between both MDD and ADL/annual personal income' being present are greater than the aORs for only one of the three factors' being present, which demonstrates that there will be much stronger association with suicidal ideation when both factors are present. The results also indicate that there is a reinforcing effect when both MDD and ADL/ annual personal income are present. This means that some people who have MDD and both low annual personal income and disabled ADL status would have higher rates of suicidal ideation; therefore we should pay more attention to these people. Ormel et $a l^{12}$ have shown three kinds of association between ADL and depression ((a) a strong contemporaneous effect of change in ADL on depressive symptoms; (b) a weaker lagged effect of change in depressive symptoms on ADL; and (c) a weak correlation between the trait (or stable) components of depression and ADL), which indicates that depression and low ADL will reinforce each other and result in much stronger association when both factors are present. Hence the three associations may explain the rationality of the existence of the interaction between MDD and ADL to a certain extent. Depression is more commonly seen in people with economic disadvantages. $^{39}$ Low socioeconomic status (SES) slightly increases the risk of episode onset and moderately increases the risk of persistence of depression. ${ }^{40}$ Besides, depression may lead to poor professional and personal outcomes. $^{41}$ It has been suggested that causation (low SES increases risk of depression) and selection (depression hinders social mobility) are not mutually exclusive explanations and that they may be combined over the life cycle. ${ }^{42} 43$ These results show that low personal income and depression will reinforce each other over a life time, and this may explain the interaction between MDD and annual personal income to some extent. Therefore, it may be a feasible way to prevent suicide behaviours by venting depressed mood and paying more attention to older people with low annual personal income and disabled ADL status.

To the best of our knowledge, this is the first study to examine the risk factors for, and their interactions with, suicidal ideation among the elderly in rural communities of China. With this population-based, large-scaled design, as well as a high rate of follow-up and highly standardised methods, these findings should be useful for preventing suicide in the aging population in rural communities of China. We provide some advice for suicide prevention in such communities: first, because of the high incidence of suicidal ideation among elderly 
individuals in rural communities, the government should pay more attention to suicidal ideation in this population; second, to reduce the rate of suicidal ideation and strengthen suicide prevention, we should strengthen venting of MDD and pay close attention to people with low income and disabled status, which should reduce the rate of suicidal ideation and also the rate of suicidal ideation caused by the interaction of risk factors. Since the study is limited by its cross-sectional design, causation cannot be inferred. It may be underpowered to address the relationships between factors and suicidal ideation and the multiple regression analyses by designed sample size. Moreover suicidal ideation is a complex psychological phenomenon, and there may be limitations to measurement accuracy and classification because we can'not use a single simple question to capture suicidal ideation. Furthermore, we cannot deny the potential bias of the self-reported design, and therefore further studies are needed to confirm the findings.

\section{CONCLUSION}

The incidence of suicidal ideation among rural-living elderly in China is high. The independent risk factors for suicidal ideation are annual personal income $(\leq 2200$ $\mathrm{CNY}$ ), MDD, chronic diseases and disabled ADL status. MDD shows additive interactions with ADL and annual personal income. The findings have significant implications for the prediction and prevention of suicidal behaviours.

Acknowledgements We thank Na Tang' for help with revising the English writing up of our study.

Contributors All the authors made substantial contributions to the whole study. HX, SX, LZ and DL were in charge of this work. All the authors took part in the conception and design. $H X, L Q$ and JW mainly analysed and interpreted the data and drafted the manuscript.

Funding This research received no specific grant from any funding agency in the public, commercial or not-for-profit sectors.

Competing interests None declared.

Patient consent Obtained.

Ethics approval The study was approved by the Medical Ethics Committee of the Clinical Pharmacology Institute at Central South University.

Provenance and peer review Not commissioned; externally peer reviewed.

Data sharing statement No additional data are available.

Open Access This is an Open Access article distributed in accordance with the Creative Commons Attribution Non Commercial (CC BY-NC 4.0) license, which permits others to distribute, remix, adapt, build upon this work noncommercially, and license their derivative works on different terms, provided the original work is properly cited and the use is non-commercial. See: http:// creativecommons.org/licenses/by-nc/4.0/

\section{REFERENCES}

1. Bertolote JM, Fleischmann A, Butchart A, et al. Suicide, suicide attempts and pesticides: a major hidden public health problem. Bulletin World Health Organ 2006:84:260.

2. Phillips MR, Li X, Zhang Y. Suicide rates in China, 1995-99. Lancet 2002;359:835-40.

3. Zhang J, Jiang C, Jia S, et al. An overview of suicide research in China. Arch Suicide Res 2002;6:167-84.
4. Wasserman D, Wasserman C. Suicidology and suicide prevention. Oxford University Press, 2009.

5. Nock MK, Borges G, Bromet EJ, et al. Cross-national prevalence and risk factors for suicidal ideation, plans and attempts. Br J Psychiatry 2008;192:98-105.

6. Phillips MR, Yang G, Zhang Y, et al. Risk factors for suicide in China: a national case-control psychological autopsy study. Lancet 2002;360:1728-36.

7. Qin $P$, Agerbo $E$, Mortensen $P B$. Suicide risk in relation to socioeconomic, demographic, psychiatric, and familial factors: a national register-based study of all suicides in Denmark, 19811997. Am J Psychiatry 2003;160:765-72.

8. Christensen H, Farrer L, Batterham PJ, et al. The effect of a web-based depression intervention on suicide ideation: secondary outcome from a randomised controlled trial in a helpline. BMJ Open 2013;3:e002886.

9. Hintikka J, Koivumaa-Honkanen $\mathrm{H}$, Lehto SM, et al. Are factors associated with suicidal ideation true risk factors? A 3-year prospective follow-up study in a general population. Soc Psychiatry Psychiatr Epidemiol 2009;44:29-33.

10. Dong $\mathrm{Y}$, Huang $\mathrm{F}, \mathrm{Hu} \mathrm{G}$, et al. The prevalence of suicidal ideation among the elderly in China: a meta-analysis of 11 cross-sectional studies. Compr Psychiatry 2014;55:1100-5.

11. Peter T, Roberts LW, Buzdugan R. Suicidal ideation among Canadian youth: a multivariate analysis. Arch Suicide Res 2008;12:263-75.

12. Ormel J, Rijsdijk FV, Sullivan M, et al. Temporal and reciprocal relationship between IADL/ADL disability and depressive symptoms in late life. J Gerontol B Psychol Sci Soc Sci 2002;57:338-47.

13. Liu $\mathrm{H}, \mathrm{He} \mathrm{Y}$, Wang J, et al. Epidemiology of depression at Traditional Chinese Medicine Hospital in Shanghai, China. Compr Psychiatry 2016;65:1-8.

14. Capron DW, Cougle JR, Ribeiro JD, et al. An interactive model of anxiety sensitivity relevant to suicide attempt history and future suicidal ideation. J Psychiatr Res 2012;46:174-80.

15. $\mathrm{Xu} \mathrm{H}$, Xiao $\mathrm{S}$, Chen J, et al. Epidemiological study on committed suicide among the elderly in some urban and rural areas of Hunan Province. Chinese Mental Health Journal 2000;8:121-4.

16. $\mathrm{Li} \mathrm{ZH}$, Xaio SY, Xiao YZ. Suicide behavior among elderly in a rural community of Hunan Province. Chin Ment Health J 2011;25:949-54.

17. Lee S, Fung SC, Tsang A, et al. Lifetime prevalence of suicide ideation, plan, and attempt in metropolitan China. Acta Psychiatr Scand 2007;116:429-37.

18. Lawton WP, Brody EM. Assessment of older people: self-maintaining and instrumental activities of daily living. Gerontologist 1969;9:179-86.

19. Liu SI, Yeh ZT, Huang HC, et al. Validation of patient health questionnaire for depression screening among primary care patients in Taiwan. Compr Psychiatry 2011;52:96-101.

20. Chen S, Chiu H, Xu B, et al. Reliability and validity of the PHQ-9 for screening late-life depression in Chinese primary care. Int J Geriatr Psychiatry 2010;25:1127-33.

21. Kroenke K, Spitzer RL, Williams JB. The PHQ-9: validity of a brief depression severity measure. J Gen Intern Med 2001;16:606-13.

22. Babor TF, Higgins-Biddle JC, Saunders JB, et al. The alcohol use disorders identification test. World Health Organization, 2001.

23. Holmes TH, Rahe RH. The social readjustment rating scale. J Psychosom Res 1967;11:213-7.

24. Paykel ES. The evolution of events research in psychiatry. J Affect Disord 2001;62:141-9.

25. Xiao S. The social support rating scale. Chin Ment Health $J$ 1999;12:127-31.

26. Andersson $\mathrm{T}$, Alfredsson $\mathrm{L}$, Källberg $\mathrm{H}$, et al. Calculating measures of biological interaction. Eur J Epidemiol 2005;20:575-9.

27. Kjoller M, Helweg-Larsen M. Suicidal ideation and suicide attempts among adult Danes. Scand J Public Health 2000;28:54-61.

28. Goldney RD, Dal Grande E, Fisher LJ, et al. Population attributable risk of major depression for Suicidal ideation in a random and representative community sample. J Affect Disord 2003;74:267-72.

29. O'Connell $\mathrm{H}, \mathrm{Chin} \mathrm{AV}$, Cunningham $\mathrm{C}$, et al. Recent developments: suicide in older people. BMJ 2004;329:895-9.

30. Shin J, Choi JW, Jang SI, et al. The temporal association of excessive health expenditure with suicidal ideation among primary income earners: a cross-sectional design using the Korean Welfare Panel Survey (KoWePS). BMJ Open 2015;5:e0007421.

31. Casey PR, Dunn G, Kelly BD, et al. Factors associated with suicidal ideation in the general population: five-centre analysis from the ODIN study. Br J Psychiatry 2006;189:410-15.

32. Cohen A, Chapman BP, Gilman SE, et al. Social inequalities in the occurrence of suicidal ideation among older primary care patients. Am J Geriatr Psychiatry 2010;18:1146-54. 
33. Feng SS, Xiao SY, Zhou L, et al. Risk factors of suicide ideation in a rural community sample of Hunan. Chin Men Health $J$ 2006;20:326-9.

34. Zimmerman FJ, Katon W. Socioeconomic status, depression disparities, and financial strain: what lies behind the income-depression relationship? Health Econ 2005;14:1197-215.

35. Awata S, Seki T, Koizumi Y, et al. Factors associated with suicidal ideation in an elderly urban Japanese population: a community-based, cross-sectional study psychiatry. Clin Neurosci 2005;59:327-36.

36. Dennis M, Baillon S, Brugha $\mathrm{T}$, et al. The influence of limitation in activity of daily living and physical health on suicidal ideation: results from a population survey of Great Britain. Soc Psychiatry Psychiat Epidemiol 2009:44:608-13.

37. Allison S, Roeger L, Martin G, et al. Gender differences in the relationship between depression and suicidal ideation in young adolescents. Aust N Z J Psychiatry 2001;35:498-503.

38. Waern M, Spak F, Sundh V. Suicidal ideation in a female population sample. Relationship with depression, anxiety disorder and alcohol dependence/abuse. Eur Arch Psychiatry Clin Neurosci 2002;252:81-5.

39. Kessler RC, Berglund P, Demler O, et al. The epidemiology of major depressive disorder: results from The National Comorbidity Survey Replication (NCS-R). JAMA 2003;289:3095-105.

40. Lorant $\mathrm{V}$, Deliège $\mathrm{D}$, Eaton $\mathrm{W}$, et al. Socioeconomic inequities in depression: a meta-analysis. Am J Epidemiol 2003;157: 98-102.

41. Turvey C, Stromquist A, Kelly K, et al. Financial loss and suicidal ideation in a rural community sample. Acta Psychiatr Scand 2002;106:373-80.

42. Eaton WW, Muntaner C. Socioeconomic stratification and mental disorder. In: Horwitz AV, Scheid TL, eds. A handbook for the study of mental health: social contexts, theories, and systems. Cambridge, UK: Cambridge University Press, 1999:259-83.

43. Kessler RC, Foster CL, Saunders WB, et al. Social consequences of psychiatric disorders, I: educational attainment. Am J Psychiatry 1995;152:1026-32. 